\title{
Reovirose aviária: um panorama
}

\section{Avian reovirus infection: an overview}

\section{Resumo}

A avicultura é um setor de grande importância na economia brasileira tanto pelo aumento do consumo interno quanto pelo crescimento na exportação de carne de frango. A modernização da atividade avícola permitiu a criação adensada de animais, facilitando, no entanto, a rápida disseminação de patógenos que reduzem os índices de produtividade dos plantéis. Nesta revisão, é destacado o reovírus aviário, importante agente de artrite em aves que apresenta distribuição mundial. As aves acometidas apresentam redução no ganho de peso devido à dificuldade de locomoção. Além da artrite, o vírus pode estar relacionado a uma variedade de condições patológicas, como distúrbios entéricos e respiratórios, hepatite e miocardite. A principal forma de prevenção e controle é a vacinação do plantel. No entanto, devido à grande variabilidade genética do reovírus aviário, a vacina utilizada pode não ser eficiente contra estirpes que circulam no campo. O artigo traz uma visão geral sobre a biologia do vírus, sua variabilidade e propostas de classificação dos isolados, patologia da doença e diagnóstico da infecção.

\section{Abstract}

Poultry production is an activity of great importance in Brazilian economy, both due to the domestic consumption and the large amount of chicken meat exportation. Poultry activity modernization allowed the creation of animals in high density facilities, however, it facilitates the rapid dissemination of pathogens, which reduces the productivity rates. This review aims to highlight the avian reovirus, an important agent of arthritis in birds that has a worldwide distribution. The affected birds present a reduction in weight gain due to movement difficulties. In addition to arthritis, the virus may be related to a variety of pathological conditions, such as enteric and respiratory disorders, Hepatitis and myocarditis. The main prevention and control measure is the flock vaccination. Nevertheless, due to the avian reovirus great genetic variability, the vaccine may not be effective against circulating strains. This article aims to overview the virus biology, its variability and classification, and the infection pathology and diagnosis. 
Tatiana Reichert da Silva Assunção

Ana Paula Gori Palka²,3

Daniela Parada Pavoni ${ }^{2,3,4}$
Rua Professor Algacyr Munhoz Mader, 3775

Curitiba/PR, CEP: 81350-010

$\checkmark$ daniela.pavoni@fiocruz.br

\section{Palavras-chave}

Reovírus aviário. Artrite viral. Avicultura.

\section{Keywords}

Avian reovirus. Viral arthritis. Poultry. avicultura industrial brasileira tem participação fundamental na economia nacional (ABPA, 2016). A carne de frango e os ovos são fontes de proteína de alta qualidade (ricos em aminoácidos essenciais), vitaminas e minerais. Apesar da pouca quantidade de ferro, a carne de frango é considerada saudável, pois é rica em gorduras poliinsaturadas ômega-3, em selênio, não contém gorduras trans e contém menor teor de gorduras saturadas que as carnes vermelhas. Além disso, em regiões que carecem de recursos básicos, os ovos são, por vezes, a única fonte de proteína animal disponível, e não necessitam de refrigeração se armazenados durante curtos períodos (FARREL, 2013a, 2013b).

Para a economia, a indústria de criação intensiva de aves representa um grande negócio e tem papel importante nas exportações do Brasil, é o mercado de carnes com maior projeção de crescimento anual. A expansão da demanda interna por produtos da avicultura deve-se ao aumento da produtividade do setor e à consequente redução do preço da carne de frango em relação às outras carnes (ABPA, 2016). A avicultura é importante para a subsistência de populações de baixa renda em países pouco desenvolvidos, além disso, a criação familiar, em baixa escala, constitui uma fonte de renda para as famílias (FARREL, 2013a).

1 Instituto Carlos Chagas - Fiocruz Paraná, Programa de Pós-Graduação em Biociências e Biotecnologia - Curitiba, Paraná, Brasil.

2 Universidade Federal do Paraná, Departamento de Biologia Celular, Programa de Pós-Graduação em Biologia Celular e Molecular - Curitiba, Paraná, Brasil.

3 Instituto de Tecnologia do Paraná - Curitiba, Paraná, Brasil.

4 Instituto Carlos Chagas - Fiocruz Paraná, Laboratório de Genômica Funcional - Curitiba, Paraná, Brasil. 
A introdução de tecnologias na produção avícola permitiu a criação adensada de uma grande quantidade de frangos (BELUSSO; HESPANHOL, 2010). Essa densidade propicia, no entanto, a rápida disseminação de patógenos, que aumenta os índices de mortalidade e morbidade, reduz o ganho de peso e gera custos adicionais com medicamentos (ALFIERI; TAMEHIRO; ALFIERI, 2000; REVOLLEDO; FERREIRA, 2009).

A artrite aviária é uma das principais causas de condenação de carcaças no abate (OLIVEIRA et al., 2016). O reovírus aviário (ARV) é um importante agente de artrite aviária/tenossinovite infecciosa e apresenta-se distribuído mundialmente (JONES, 2000).

No Brasil, o primeiro isolado do ARV foi obtido por Bottino e colaboradores em 1975, com galinhas de postura e frangos de corte com processos inflamatórios. Embora a mortalidade pelo ARV não seja significativa, a sua morbidade pode chegar a $100 \%$. Na fase de produção, as artrites/tenossinovites infecciosas têm como principais consequências a redução no ganho de peso, a piora na conversão alimentar e transtornos de locomoção, por conta dos quais as aves podem morrer por inanição e desidratação (JONES, 2000).

A reovirose aviária não é uma doença de notificação compulsória no Brasil, mas a infecção por ARV deixa o animal susceptível a outras infecções. Além disso, há uma crescente exigência por parte de países importadores de que se comprove que a carne exportada tenha sido submetida a controles sanitários e esteja livre de patógenos.

\section{Características do reovírus aviário (ARV)}

O ARV está classificado na família Reoviridae e no gênero Orthoreovirus (ATTOUI et al., 2012). As letras iniciais "REO" do nome "reovírus" referem-se à primeira descrição de vírus isolados de mamíferos no México e nos Estados Unidos da América, em 1950: "Respiratory and Enteric Orphan viruses" (DAY, 2009).

O material genético viral é RNA de dupla-fita (dsRNA), segmentado, envolto por um capsídeo duplo de natureza proteica e simetria icosaédrica, com cerca de $80 \mathrm{~nm}$ de diâmetro. O genoma é composto por dez segmentos, cujos tamanhos variam de 1 a 4 quilobases $(\mathrm{kb})$, agrupados em três classes, de acordo com o tamanho: L1, L2 e L3, da classe L (large); M1, M2 e M3, da classe M (medium); e $S 1$, S2, S3 e S4, da classe S (small). As proteínas codificadas pela classe L são denominadas lambda $(\lambda)$, as codificadas pela classe $M$ são denominadas mi $(\mu)$, e proteínas codificadas pela classe $S$ são denominadas sigma $(\sigma)$ (SPANDIDOS; GRAHAM, 1976; VARELA; BENAVENTE, 1994). Há uma correspondência entre segmentos gênicos e produtos proteicos, cada segmento de RNA codificando uma proteína, com exceção do segmento $\mathrm{M} 2$, que codifica um produto proteico, $\mu \mathrm{B}$, que sofre uma clivagem gerando mais duas proteínas, $\mu \mathrm{BN}$ e $\mu \mathrm{BC}$, e do segmento S1, que codifica três proteínas (BODELÓN et al., 2001; MARTÍNEZ-COSTAS et al., 1997).

A Figura 1 esquematiza a partícula viral, com a localização e função individual das 10 proteínas estruturais que fazem parte do vírion maduro ( $\mu \mathrm{B}$ e seus produtos, $\mu \mathrm{BN}$ e $\mu B C$, estão representadas como um só elemento). Além delas, o ARV expressa quatro proteínas não estruturais, presentes apenas nas células infectadas (MARTÍNEZCOSTAS et al., 1997; VARELA; BENAVENTE, 1994).

$\mathrm{O} A R V$ resiste às temperaturas de $60^{\circ} \mathrm{C}$, por 8 a $10 \mathrm{~h}$; $56^{\circ} \mathrm{C}$, por 22 a $24 \mathrm{~h} ; 37^{\circ} \mathrm{C}$, por 15 a 16 semanas; $22^{\circ} \mathrm{C}$, por 48 a 51 semanas; $4^{\circ} \mathrm{C}$, por mais de três anos; $-20^{\circ} \mathrm{C}$, por mais de quatro anos; e $-63^{\circ} \mathrm{C}$, por mais de 10 anos (OLSON; KERR, 1967; JONES, 2008, p. 311). A partícula viral sobrevive por até 10 dias em penas, madeiras, superfície de cascas de ovos e ração. $\mathrm{Na}$ água, os vírus podem sobreviver por até 10 semanas, com pouca perda de capacidade infecciosa (SAVAGE; JONES, 2003).

O ARV apresenta resistência a $\mathrm{pH}$ baixo, ao peróxido de hidrogênio, ao lisol $2 \%$, à formalina, aos inibidores metabólicos de DNA actinomicina-D, à citosina arabinose e à 5-fluoro-2-deoxiuridina. No entanto, a partícula viral é sensível ao etanol $70 \%$ e ao iodo orgânico $0,5 \%$ (NEIGHBOR et al., 1994).

\section{Ciclo de vida do vírus}

O primeiro passo para a infecção celular é a interação entre a proteína $\sigma \mathrm{C}$ (Figura 1) e os receptores celulares ainda não identificados, o que desencadeia a internalização da partícula viral (GRANDE et al., 2000) (Figura 2). Uma vez dentro da célula, ocorre a remoção total ou parcial do capsídeo externo, processo conhecido como desnudamento, em decorrência da temperatura celular e do ambiente ácido e de enzimas presentes no compartimento em que o vírus se encontra (DUNCAN, 1996; GRANDE; BENAVENTE, 2000). A interação de proteínas virais (produtos de clivagem da proteína $\mu \mathrm{BC}$ ) com a membrana desse compartimento celular determina sua lise, e o capsídeo interno é liberado para o citoplasma da célula (DUNCAN, 1996). Os RNAs mensageiros (mRNA) virais são sintetizados no interior do capsídeo e provavelmente saem da partícula viral por meio de canais formados pelos pentâmeros da proteína $\lambda \mathrm{C}$ (Figura 1). Essa proteína adiciona um cap à extremidade de cada mRNA, necessário para que eles sejam reconhecidos pelos ribossomos celulares (MARTÍNEZ-COSTAS; VARELA; BENAVENTE, 1995; ZHANG et al., 2005). Então, as moléculas de mRNA são usadas para a produção de proteínas virais ou são incorporadas nas partículas virais 
recém-sintetizadas, servindo de molde para a formação das duplas-fitas de RNA (dsRNA), que constituirão o genoma viral (BENAVENTE; MARTÍNEZ-COSTAS, 2007).

A replicação viral e a montagem das partículas virais recém-sintetizadas ocorrem dentro de inclusões globulares no citoplasma das células conhecidas como "fábricas virais" ou "inclusões virais" (SILVERSTEIN; SCHUR, 1970).
A síntese das proteínas virais pode ser detectada já nos estágios iniciais da infecção por ARV e, posteriormente, a maior parte das proteínas sintetizadas pela célula hospedeira são de origem viral (BENAVENTE; MARTÍNEZ-COSTAS, 2007). Após a formação das partículas de ARV, os vírus são liberados com a lise celular (BODELÓN et al., 2002).
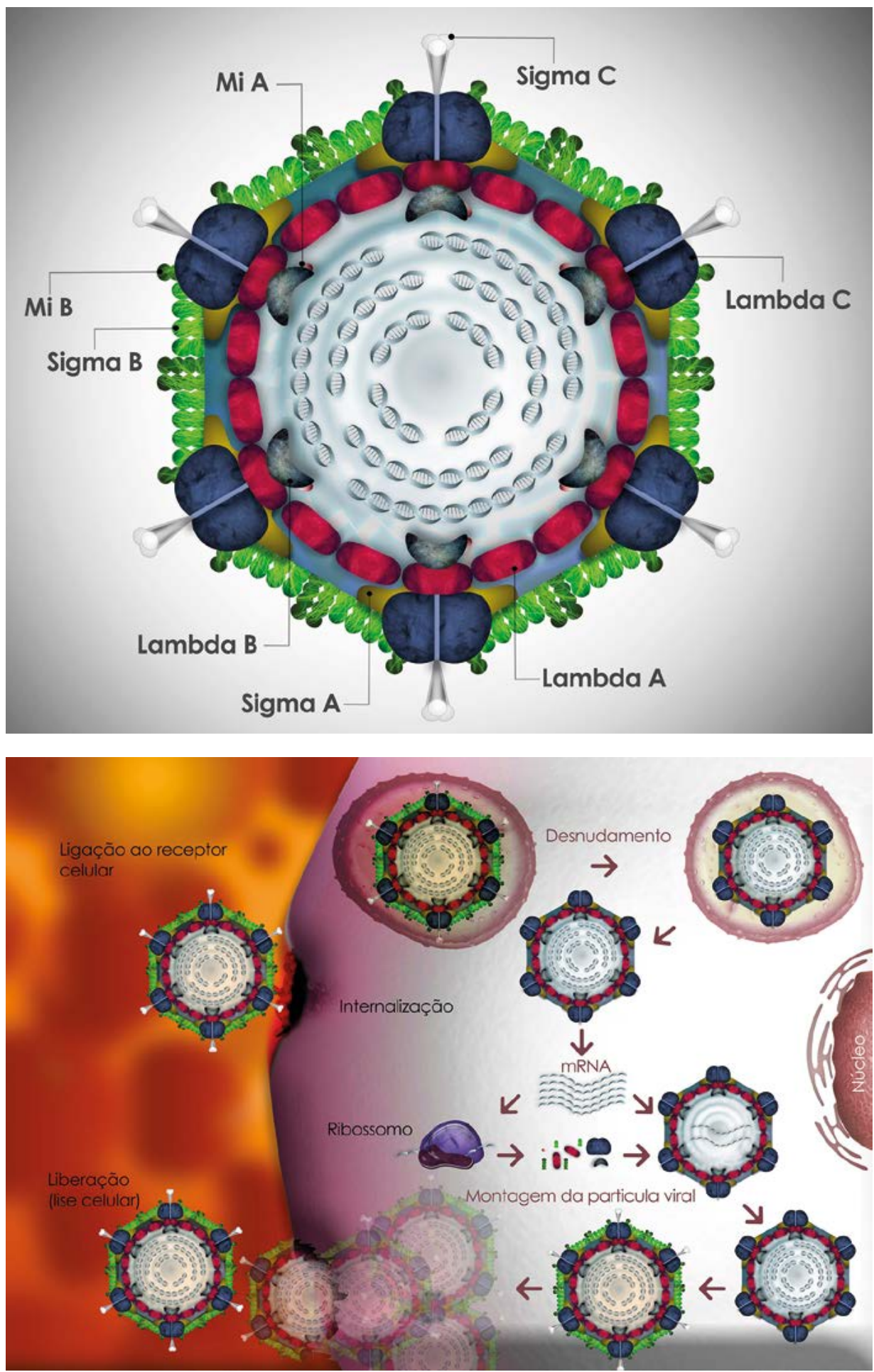

Figura 1 - Representação esquemática do vírion do ARV. A partícula viral possui tamanho em torno de 80nm, e é formada por 2 capsídeos proteicos: um externo, representado em verde, tendo como base as proteínas $\mu \mathrm{B}$ (com seus subprodutos de clivagem, $\mu \mathrm{BN}$ e $\mu B C$ ) e $\sigma B$; e um interno, em rosa, que tem como esqueleto a proteína $\lambda A$. A proteína $\lambda C$ (azul) forma 12 projeções pentaméricas localizadas ao redor de cada um dos 12 vértices do icosaedro. Associando-se à porção externa do pentâmero, localiza-se a proteína $\sigma C$. Os segmentos de dsRNA, estão dispostos em anéis concêntricos no interior da partícula. A RNA polimerase e seu cofator (proteínas $\lambda B$ e $\mu A$ ) estão dispostos no interior da partícula em 10 a 12 dos vértices do icosaedro.

Fonte: Elaboração das autoras.
Figura 2 - Ciclo celular do ARV. O ciclo replicativo do ARV inicia-se com a ligação dos vírions a receptores celulares ainda não identificados. Após internalização, ocorre o desnudamento dos vírions e inicia-se o processo de transcrição. As moléculas de mRNA recém-sintetizadas serão utilizadas para síntese de proteínas virais ou recrutadas para o interior das partículas recém-formadas, servindo como molde para a síntese de dsRNA dos novos vírions. A partícula viral madura é então liberada através de lise celular. Fonte: Elaboração das autoras. 


\section{Patogenia e sinais clínicos da infecção}

O ARV está comprovadamente associado à artrite viral/ tenossinovite infecciosa (Figura 3). As lesões articulares de caráter inflamatório crônico fazem as aves acometidas apresentarem inchaço nos tendões e nas articulações, geralmente com presença de exsudato amarelo, ou tingido de sangue. Petéquias podem ser frequentes nas membranas sinoviais do jarrete (JONES, 2008, p. 314; VASCONCELOS et al., 2001). Em casos mais graves, ocorre erosão da cartilagem articular e ruptura do tendão gastrocnêmico (JONES, 2000).

A natureza da doença das aves infectadas por ARV, bem como o período de incubação do vírus, estão diretamente relacionados à idade da ave acometida, ao status imune do hospedeiro, à estirpe viral e à via de infecção (MUKIIBI-MUKA; JONES, 1999; ROSENBERGER et al., 1989). O tropismo tecidual do ARV é determinado geneticamente e está relacionado a mutações no segmento genômico S1, que codifica a proteína $\sigma \mathrm{C}$ (MEANGER et al., 1999). As lesões observadas em vários tecidos de aves infectadas, como coração, fígado, baço, rins, bursa de Fabricius, articulações e medula óssea, são consequências da replicação do vírus (NI; RAMIG; KEMP, 1993). Monócitos e macrófagos também são alvos de infecção viral, e isto pode explicar o aumento da susceptibilidade dos animais a infecções secundárias de origem bacteriana (CHEN et al., 2015).

As aves acometidas apresentam transtornos de locomoção, permanecendo em decúbito ventral, com consequente alteração da conversão alimentar e ganho de peso, resultando em mortalidade por inanição e desidratação (JONES, 2000; BENAVENTE; MARTÍNEZ-COSTAS, 2007). O desenvolvimento de artrite viral em matrizes imediatamente antes ou durante a postura pode resultar em: claudicação, diminuição da produção de ovos, fertilidade e eclodibilidade sub-ótimas, bem como transmissão vertical do reovírus e consequente aumento da mortalidade da progênie (DOBSON; GLISSON, 1992).

Aves jovens, com até duas semanas, são mais susceptíveis ao ARV e desenvolvem lesões mais severas do que aves adultas. A resistência à infecção aumenta de forma linear em relação ao aumento de idade, mas as aves podem desenvolver doença menos severa e com período de incubação mais prolongado. A resistência à infecção provavelmente está associada à maturação da resposta imune humoral, que combate a disseminação do vírus e reduz a destruição celular nos tecidos de forma mais eficaz (ROESSLER; ROSENBERGER, 1989).

Além das manifestações relatadas, que são as mais conhecidas da reovirose aviária, o vírus também tem sido isolado de vários tecidos de aves acometidas por uma variedade de condições patológicas, como distúrbios entéricos e respiratórios, hepatite, miocardite, pancreatite, doenças do sistema nervoso central e síndrome da má-absorção, condição de etiologia multifatorial com sinais clínicos variáveis como diarreia, crescimento atrofiado, alteração no padrão das penas (penas eriçadas), fraqueza, alterações hepáticas e pancreáticas e enterite. $\mathrm{O}$ exato papel do ARV nessas patologias, entretanto, necessita ser melhor esclarecido para que a significância clínica do vírus seja avaliada (DANDÁR et al., 2013; GOODWIN et al., 1993; JONES, 2000).

Infecções concomitantes com outros agentes podem resultar em alterações na natureza e na severidade da doença. Agentes infecciosos como Escherichia coli, Mycoplasma synoviae, Staphylococcyus aureus e vírus da anemia infecciosa podem aumentar o efeito patogênico de ARV nas articulações e aumentar consideravelmente os índices de mortalidade (BACK, 2002; DE HERDT et al., 2008; ENGSTRÖM; FOSSUM; LUTHMAN, 1988).

\section{Vias de transmissão do ARV}

A transmissão horizontal é a principal via de transmissão do ARV, que pode ocorrer de forma direta, de ave para ave, ou indireta, em virtude da presença do agente infeccioso no ambiente, havendo variação considerável entre as estirpes virais em relação às respectivas capacidades de propagação (JONES, 2000). Apesar de haver excreção viral por vias intestinal e respiratória, a presença prolongada do agente no intestino das aves infectadas sugere a via fecal-oral como principal mecanismo de transmissão (JONES; ONUNKWO, 1978). A transmissão vertical ocorre em taxas bem inferiores (AL-MUFFAREJ et al., 1996).
A

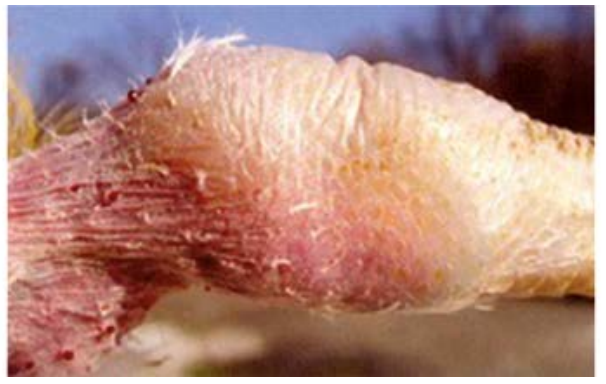

B

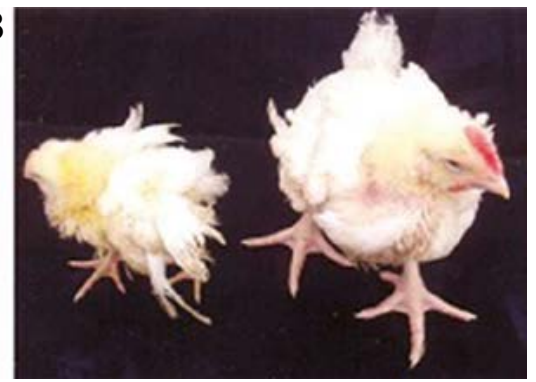

Figura 3 - Sinais clínicos de infecção por ARV em uma ave: Inchaço na articulação (A) e desuniformidade do plantel resultante da redução de ganho de peso (B). Fonte: Dinev (2007) 
As partículas virais podem permanecer por várias semanas tanto no intestino, como também em outros tecidos do hospedeiro, com destaque para o jarrete e a cloaca. Em aves saudáveis que entraram em contato com aves infectadas, o vírus foi detectado no duodeno e jarretes, uma a seis e 13 semanas após o contato, respectivamente, demonstrando o papel das aves contaminadas como fonte de infecção para o plantel (JONES; ONUNKWO, 1978). Também já foi descrita a entrada do reovírus no hospedeiro devido ao rompimento da barreira epitelial das patas de aves domésticas e estabelecimento da infeção nos jarretes (AL-AFALEQ; JONES, 1990).

\section{Incidência do ARV}

Apesar do ARV ter sido isolado de aves com variedade de condições patológicas, ele também tem sido isolado de aves aparentemente saudáveis (JONES, 2000). Anticorpos anti-reovírus foram identificados em aves que não apresentam sinais clínicos. A infecção por ARV, na ausência de doença, sugere que o isolamento do vírus nos tecidos da ave não implica necessariamente que ele esteja causando doença. Tal fato pode estar relacionado a diferentes graus de virulência das diferentes estirpes do vírus (JONES, 2000; ROBERTSON; WILCOX; KIBENGE, 1984). Isto indica que o vírus pode estar mais disseminado do que se estivesse restrito às aves doentes.

Estudos que avaliam a incidência do vírus em plantéis de aves têm que ser analisados levando em consideração que os resultados dependem do tipo de teste aplicado (se para detectar o vírus ou os anticorpos), a abrangência do teste (testes direcionados a algumas estirpes podem não detectar outras) e o histórico de vacinação. De qualquer forma, a análise dos dados publicados pode dar uma ideia da situação mundial. Mas como pode ser observado a seguir, a incidência do ARV varia de estudo para estudo, dependendo do local e, em geral, não é baixa.

Em frangos de corte e em matrizes, foi detectada soroprevalência de $41 \%$ na Nigéria (OWADE; DUCATEZ; MULLER, 2006), em Bangladesh, 47\% (BISWAS et al., 2009), na China, 92\% (PU et al., 2008), e no Irã, 98\% (BOKAIE et al., 2008).

Nos Estados Unidos, o vírus foi detectado em $63 \%$ das aves (PANTIN-JACKWOOD et al., 2008).

No Brasil, poucos estudos têm sido realizados com a finalidade de identificar a distribuição do vírus, bem como as estirpes circulantes. No estado de Minas Gerais, foi investigado o conteúdo intestinal de 54 aves com sintomatologia compatível com reovirose, e em 9,3\% foi detectado o ARV. O mesmo grupo examinou amostras fecais de aves não vacinadas e com sintomas intestinais em várias regiões do estado do Paraná, obtidas entre 1997 e 1999, e observou a presença de infecção por ARV em 1,8\%, não sendo detectado o ARV nas amostras obtidas de aves saudáveis (ALFIERI et al., 1989; TAMEHIRO et al., 2003).

No estado do Rio Grande do Sul, foi detectada a presença de anticorpos contra ARV em 21,6\% das aves examinadas, sem histórico de vacinação (SANTOS et al., 2008). A análise da presença de ARV entre outros vírus em várias regiões do estado de Minas Gerais, em amostras fecais tanto de aves saudáveis quanto de aves com sintomatologia, como alteração no crescimento e claudicação, indicou 5,6\% de positividade (RIOS et al., 2012). Em amostras fecais de aves localizadas no estado do Pará, sem histórico de vacinação, o índice de positividade foi de 32,9\% (SILVA, 2012). Já em Santa Catarina, a análise de amostras teciduais de aves provenientes de granjas comerciais, não vacinadas e com sintomas de inflamação tibiotársica, detectou o ARV em 25,5\% das aves (RECK et al., 2013).

Em diversos estados brasileiros (Rio Grande do Sul, Minas Gerais, São Paulo, Paraná, Pará, Rio de Janeiro, Santa Catarina, Goiás e Ceará), o ARV foi detectado em $7,9 \%$ dos conteúdos intestinais das aves examinadas, concomitantemente, ou não, com outros vírus (METTIFOGO et al., 2014).

\section{ARV em outras espécies de aves}

Além do isolamento do ARV em galinhas (Gallus gallus domesticus), estudos epidemiológicos têm demonstrado a distribuição mundial do ARV em várias espécies de aves, tanto saudáveis como doentes (JONES, 2000).

$\mathrm{O}$ vírus foi isolado de perus domésticos (Meleagris gallopavo) e de várias espécies de aves selvagens (JONES, 2000; SANTOS et al., 2009), em vários pontos do globo terrestre. O ARV foi associado a surtos de pancreatite em galinhas d'angola (Numida meleagris), na Hungria (TANYI et al., 1994); em alterações hepáticas em patos selvagens (Cairina moschata), em Israel (MALKINSON; PERK; WEISMAN, 1981); e em patos da espécie Somateria molíssima, na Finlândia (HOLLMÉN et al., 2002).

$\mathrm{Na}$ Holanda, a reovirose aviária foi detectada em várias espécies de papagaios e periquitos que apresentavam altos índices de mortalidade e que, à necropsia, apresentavam hepatomegalia e esplenomegalia severas, com necrose multifocal (VAN DEN BRAND et al., 2007). Um surto de reovirose aviária foi descrito na Espanha em papagaios africanos (Psittacus erithacus) com sintomas respiratórios (SÁNCHEZ-CORDÓN et al., 2002).

$\mathrm{Na}$ Hungria, o ARV foi identificado em gansos jovens com alterações articulares (PALYA et al., 2003); na Grã-Bretanha, em pombos com hepato e esplenomegalia (LAWSON et al., 2015); e em Taiwan, em pombos aparentemente saudáveis (TSAI; LEE, 2006). 
No Rio Grande do Sul, Brasil, foram detectados anticorpos contra ARV em 15,7\% de aves silvestres mantidas em criatórios conservacionistas e zoológicos: Jacu (Penelope obscura), Jacutinga (Pipile jacutinga), Mutum-cavalo (Mitu tuberosa) e Mutum-pinima (Crax fasciolata pinima) (SANTOS et al., 2009).

Algumas estirpes de ARV isoladas de patos e águias causaram alterações patológicas (especialmente nas articulações de jarretes) em galinhas, sugerindo a possibilidade de transmissão interespécies (JONES; GUNERATNE, 1984). No entanto, o papel de aves silvestres como reservatórios do vírus ainda não foi suficientemente estudado (JONES, 2000).

\section{Classificação dos isolados virais}

Muitas estirpes do ARV já foram identificadas em aves em várias regiões do mundo desde o primeiro isolado do vírus por Fahey e Crawley em 1954, e novas variantes continuam a ser identificadas (TROXLER et al., 2013; VAN DE ZANDE; KUHN, 2007). As estirpes patogênicas de ARV comumente citadas são: S1133, 1733, 2408, 138, 176, 1017-1, RAM-1, Reo 25 (JONES, 2000; LIU et al., 2003). Com um número cada vez maior de isolados, percebe-se que estirpes isoladas podem ser agrupadas de acordo com algumas características.

Em uma proposta de classificação que levou em consideração a patogenicidade do vírus por infecção experimental, os isolados foram agrupados em três patotipos distintos: patotipo I (estirpes que levam à síndrome da má-absorção, como a 2408), patotipo II (causam artrite viral, como a S1133) e patotipo III (causam as duas alterações, artrogênicas e digestivas, como a 1733) (CLARK et al., 1990).

Há outra classificação do ARV, que além de avaliar os sinais clínicos, também considera o índice de mortalidade, a diminuição de ganho de peso, as lesões teciduais e a invasibilidade e persistência dos vírions em aves SPF (specific pathogen free), inoculadas experimentalmente com um dia de idade. As estirpes foram classificadas como de baixa patogenicidade (como a 2177), patogenicidade intermediária (como as S1133 e 2035) e alta patogenicidade (como as 1733 e 2408) (ROSENBERGER et al., 1989).

Algumas classificações de diferentes isolados do vírus ARV foram estabelecidas por sorologia que utilizaram testes de neutralização, agrupando, então, as estirpes em sorotipos (HIERONYMUS; VILLEGAS; KLEVEN, 1983; ROBERTSON; WILCOX, 1984; WOOD et al., 1980). As proteínas de ARV que induzem a produção de anticorpos neutralizantes e que, por conseguinte, estão envolvidas com inibição de infectividade viral, são $\sigma \mathrm{C}, \sigma \mathrm{B}$ e $\lambda \mathrm{C}$ (YANG et al., 2010). Porém, a considerável heterogeneidade dessas proteínas tem dificultado a classificação das estirpes de
ARV por meio da caracterização sorológica, resultando em grande número de reações cruzadas em testes de neutralização (BENAVENTE; MARTÍNEZ-COSTAS, 2007; CLARK et al., 1990).

Algumas tentativas para classificar as estirpes de ARV têm empregado técnicas moleculares de análise do material genético, uma vez que a sequência proteica é um reflexo da sequência do material genético (KORT et al., 2015; LIU et al., 2004; LIU; GIAMBRONE; NIELSEN, 1997). A caracterização de isolados de ARV com base nas sequências dos segmentos $\mathrm{S}$ ou da sequência aminoacídica da proteína $\sigma \mathrm{C}$, codificada pelo segmento $\mathrm{S} 1$, permitiu a classificação dos isolados analisados em grupos distintos. As estirpes mais utilizadas em vacinas comerciais (S1133, 1733 e 2408) apresentam íntima associação entre si e foram alocadas no mesmo grupo, independente da sequência gênica utilizada na sua classificação (GOLDENBERG et al., 2010; LIU et al., 2003, 2004; LIU; GIAMBRONE; NIELSEN, 1997).

O ARV, um vírus cujo material genético é RNA, está sujeito a altas taxas de mutações, devido à falta de mecanismos de correção da sua enzima, a RNA polimerase. Por isso, os isolados apresentam considerável divergência entre si e é difícil estabelecer associações entre as diferentes classificações baseadas em genótipo, características de patogenicidade ou classificação sorológica (CLARK et al., 1990; KANT et al., 2003; KORT et al., 2015). O cenário fica ainda mais complexo, pois as linhagens cocirculantes em um mesmo hospedeiro podem se recombinar, gerando partículas virais com combinações de segmentos gênicos diferentes, ou seja, novas variantes surgem com constelações distintas de genes (LIU et al., 2003).

De qualquer forma, a caracterização e a classificação dos isolados de ARV são importantes recursos a serem utilizados tanto nos estudos epidemiológicos como para escolha de vacinas, uma vez que a vacinação oferece proteção apenas contra as estirpes que possuem similaridade no que se refere aos antígenos reconhecidos pelos anticorpos neutralizantes (RAU et al., 1980; JONES, 2000).

\section{Diagnóstico da infecção por ARV}

As lesões ocasionadas pelo ARV não são patognomônicas e são semelhantes às lesões causadas por $S$. aureus e $M$. synoviae. Além disso, esses agentes também podem estar presentes associados ao reovírus nas lesões articulares (JONES, 2000). Histologicamente, as alterações ocasionadas pelo reovírus são predominantemente caracterizadas por inflamação difusa, já aquelas ocasionadas por estafilococos, são focais e purulentas (HILL et al., 1989).

A confirmação da infecção por ARV requer a realização de testes laboratoriais. O isolamento viral, considerado 
padrão-ouro para o diagnóstico de infecção por ARV, pode ser realizado a partir de amostras de fezes ou teciduais, como de traqueia, fígado, bursa de Fabricius, rins e baço. Quando a suspeita é de artrite viral, os tecidos mais utilizados para o isolamento são partes do osso sesamoide e tendões que passam por ele, membrana sinovial e cartilagem articular (JONES; GEORGIOU, 1984b). O isolamento e identificação do vírus em amostras teciduais não é utilizado na rotina de diagnóstico por ser uma técnica laboriosa e, por isso, outros métodos mais rápidos têm sido empregados (JONES, 2000; TAMEHIRO et al., 2003; YANG et al., 2010).

A detecção de anticorpos em resposta à infecção por ARV em aves tem sido um importante procedimento diagnóstico, e a amostra utilizada é o soro/plasma. Além disso, a quantificação de anticorpos também pode permitir a determinação do status imune em um plantel e indicar o momento ideal para vacinação das aves (LIU et al., 2002; SHIEN; YIN; LEE, 2000; YANG et al., 2010).

Inicialmente, a resposta de anticorpos direcionados ao ARV era determinada por vírus neutralização e imunodifusão, porém, apesar de serem úteis no diagnóstico da infecção, são métodos laboriosos e demorados (SHIEN; YIN; LEE, 2000; WOOD et al., 1980). Outros testes com maior praticidade, como immunoblot, imunofluorescência e western blot já foram desenvolvidos para o diagnóstico da infecção por ARV (IDE, 1982; ENDO-MUNOZ, 1990).

Os ensaios imunoenzimáticos do tipo ELISA (enzyme-linked immunosorbent assay) surgiram como um recurso sensível e eficiente para detecção de anticorpos anti-reovírus aviário e passaram a ser o método de escolha para triagem de grande número de amostras, uma vez que este processo pode ser automatizado e apresenta alta reprodutibilidade (LIU et al., 2002; SHIEN; YIN; LEE, 2000; XIE et al., 2010).

O macerado viral é usualmente o antígeno utilizado para sensibilizar as placas de ELISA, entretanto, testes utilizando proteínas recombinantes do ARV, em substituição ao macerado viral, têm sido desenvolvidos e disponibilizados comercialmente. A vantagem da utilização de proteínas recombinantes é a biosseguridade na confecção do teste, uma vez que não há necessidade de manipular o vírus e há aumento da sensibilidade e especificidade do ensaio. A análise da utilização das proteínas $\sigma \mathrm{B}, \sigma \mathrm{C} \mathrm{e}$ $\sigma \mathrm{NS}$ recombinantes para o diagnóstico de infecção por ARV e monitoramento da vacinação no plantel tem sido realizada (LIU et al., 2002; SHIEN; YIN; LEE, 2000; XIE et al., 2010; YANG et al., 2010).

Técnicas moleculares para detecção do RNA viral, como hibridização in situ e reações em cadeia da polimerase (PCR), já foram desenvolvidas para o diagnóstico da infecção por ARV (HUANG et al., 2015; LIU et al., 1999; RECK et al., 2013). Nesses casos, as amostras usadas, como fezes e tecidos, devem conter as partículas virais.

\section{Prevenção e controle}

Devido ao fato de o ARV apresentar-se distribuído mundialmente, de ser relativamente resistente no ambiente e ser transmissível tanto por via vertical quanto horizontal, manter um plantel de aves comerciais livre de infecção viral requer bastante esforço. Embora a principal abordagem para controle da infecção em aves seja a vacinação, o manejo correto e o emprego de procedimentos de biosseguridade, como limpeza e desinfecção eficaz, são pontos chaves para minimizar a ocorrência de infecções (JONES, 2000).

Não existe tratamento específico para infecção por ARV e a vacinação torna-se, então, um importante recurso para prevenção e controle da doença (JONES, 2000). Uma vez que as aves em geral apresentam resistência natural à infecção com poucas semanas de idade, as vacinas e programas de vacinação são direcionados para proverem a proteção aos pintos nos primeiros dias de vida (JONES, 2000; JONES; GEORGIOU, 1984a). Os esquemas de vacinação para ARV são normalmente realizados em pintos de um dia de idade ou em reprodutoras, as quais transferem os anticorpos aos pintos por via vertical (VAN DER HEIDE; KALBAC; HALL, 1976; VAN LOON et al., 2003).

Deve-se ressaltar, no entanto, que a vacinação contra o ARV oferece proteção completa somente para as estirpes de um mesmo sorotipo, o que foi demonstrado experimentalmente (LUBLIN et al., 2011; MEANGER et al., 1997; RAU et al., 1980). A disseminação de vírus para regiões onde as estirpes circulantes são de grupos sorológicos distintos, ou o surgimento de variantes novas com alterações nas proteínas imunogênicas, visto que o vírus possui alta capacidade de mutação e de rearranjos genéticos, pode comprometer o programa de vacinação previamente estabelecido e ocasionar surtos de reovirose (LIU et al., 2003; LUBLIN et al., 2011; TROXLER et al., 2013).

A vacina desenvolvida por van der Heide e colaboradores (1983), empregando a estirpe S1133 isolada, nos EUA, é a base de muitas vacinas comerciais disponíveis na atualidade e tem sido utilizada isoladamente ou em combinação com outras, como 1733, 2408 e 2177 (JONES, 2000; GOLDENBERG et al., 2011). Essas estirpes são atualmente utilizadas na maioria das vacinas comerciais para ARV, inclusive no Brasil, e não representam a diversidade de grupos sorológicos descritos atualmente (GOLDENBERG et al., 2010; KANT et al., 2003; LIU et al., 2003).

Lublin e colaboradores (2011) avaliaram a utilização de uma vacina contendo um vírus representante de cada 
grupo definido com base na variabilidade da sequência codificadora da proteína oC (GOLDENBERG et al., 2010). Foi demonstrado que esta vacinação conferiu maior proteção que a vacinação com apenas uma estirpe.

Atualmente têm sido desenvolvidas vacinas recombinantes, que empregam não mais o vírion completo, mas as proteínas ou fragmentos proteicos que induzem a produção de anticorpos neutralizantes. Com essa estratégia, o esquema de vacinação pode ser ajustado de acordo com o surgimento de novas estirpes, uma vez que a produção de vacinas utilizando o vírus inteiro é um processo demorado e, no caso de vírus que apresentam altas taxas de mutações, o procedimento é bastante laborioso, ou impraticável (CORREIA et al., 2014; GOLDENBERG et al., 2016).

\section{Desafios no Brasil}

No Brasil, na atualidade, há uma carência de estudos avaliando a distribuição do ARV. Provavelmente o vírus está bastante disseminado, principalmente entre as aves de pequenos agricultores e produtores orgânicos que não utilizam nenhuma vacina. Os programas de vacinação são pragmáticos, fornecendo a sensação aos produtores de que o plantel está protegido. A vacina, todavia, como já explicitado, não protege contra todos os sorotipos e estirpes de reovírus que podem estar circulando, mesmo entre os plantéis vacinados. Necessita-se, em um primeiro momento, realizar estudos de epidemiologia molecular com o intuito de sequenciar e caracterizar as variantes presentes no país. Em um segundo momento, há a necessidade de desenvolver soluções diagnósticas e vacinas apropriadas à realidade brasileira.

\section{Agradecimentos}

Os autores agradecem a Wagner Nagib pelo design gráfico das figuras da partícula do vírion e do ciclo celular do ARV. (:)

\section{Referências}

ABPA - ASSOCIAÇÃO BRASILEIRA DE PROTEÍNA ANIMAL. Relatório anual 2016. São Paulo: ABPA, 2016. Disponível em: $<$ https://bit.ly/1U40cdp>. Acesso em: $1^{\circ}$ nov. 2016.

AL-AFALEQ, A. I.; JONES, R. C. Localisation of avian reovirus in the hock joints of chicks after entry through broken skin. Research in Veterinary Science, Amsterdam, v. 48, n. 3, p. 381-382, 1990.

ALFIERI, A. F. et al. Detection and propagation of avian enteric reovirus in chickens. Arquivo Brasileiro de Medicina Veterinária e Zootecnia, Belo Horizonte, v. 41, n. 6, p. 493-501, 1989.

ALFIERI, A. F.; TAMEHIRO, C. Y.; ALFIERI, A. A. Vírus entéricos RNA fita dupla, segmentado, em aves: rotavírus, reovírus e picobirnavírus. Semina: Ciências Agrárias, Londrina, v. 21, n. 1, p. 101-113, 2000.

AL-MUFFAREJ, S. I. et al. Egg transmission of avian reovirus in chickens: comparison of a trypsin-sensitive and a trypsin resistant strain. Avian Pathology, Abingdon, v. 25, p. 469-480, 1996.

ATTOUI, H. et al. Sequence characterization of Ndelle virus genome segments 1, 5, 7, 8 and 10: evidence for reassignment to the genus Orthoreovirus, family Reoviridae. Biochemical and Biophysical Research Communications, New York, v. 287, p. 583588, 2001.

BACK, A. Manual de doenças de aves. Cascavel: Integração, 2002. 311 p.

BELUSSO, D.; HESPANHOL, A. N. A evolução da avicultura industrial brasileira e seus efeitos territoriais. Revista Percurso, Maringá, v. 2, n. 1, p. 25-52, 2010.

BENAVENTE, J.; MARTÍNEZ-COSTAS, J. Avian reovirus: structure and biology. Virus Research, Amsterdam, v. 123, n. 2, p. 105-119, 2007.

BISWAS, P. K. et al. Serosurvey of five viruses in chickens on smallholdings in Bangladesh. Preventive Veterinary Medicine, Amsterdam, v. 88, n. 1, p. 67-71, 2009.

BODELÓN, G. et al. The avian reovirus genome segment S1 is a functionally tricistronic gene the express one structural and two nonstructural proteins in infected cells. Virology, New York, v. 290, n. 2, p. 181-191, 2001.

Modification of late membrane permeability in avian Reovirus-infected cells. The Journal of Biological Chemistry, Rockville, v. 277, n. 17, p. 17789-17796, 2002.

BOKAIE, S. et al. Seroprevalence survey on reovirus infection of broiler chickens in Tehran province. Iranian Journal of Veterinary Research, Shiraz, v. 9, n. 2, p. 181-183, 2008.

BOTTINO, J. A. et al. Agente viral isolado de casos de artrite em frangos de corte e em galinhas de postura. O Biológico, São Paulo, v. 41 , p. $168-169,1975$.

CHEN, Y. S. et al. Avian reovirus replication in mononuclear phagocytes in chicken footpad and spleen after footpad inoculation. The Canadian Journal of Veterinary Research, Ottawa, v. 79, n. 2, p. 87-94, 2015.

CLARK, F. D. et al. Characterization of avian reovirus strain-specific polymorphisms. Avian Diseases, Jacksonville, v. 34, n. 2, p. 304314, 1990.

CORREIA, B. E. et al. Proof of principle for epitope-focused vaccine design. Nature, London, v. 507, n. 7491, p. 201-206, 2014.

DANDÁR, E. et al. Detection and characterization of a divergent avian reovirus strain from a broiler chicken with central nervous system disease. Archives of Virology, New York, v. 158, n. 23, 2013. 
DAY, J. M. The diversity of the orthoreoviruses: molecular taxonomy and phylogentic divides. Infection, Genetics and Evolution, Amsterdam, v. 9, n. 4, p. 390-400, 2009.

DE HERDT, P. et al. Field experiences with ERS type reovirus infections in diseased broilers reared under Western European filed circumstances. Vlaams Diergeneeskundig Tijdschrift, Gent, v. 78, p. 171-175, 2008.

DINEV, I. Diseases of poultry: a colour atlas. Sheffield: 5m, 2007.

DOBSON, K. N.; GLISSON, J. R. Economic impact of a documented case of reovirus infection in broiler breeders. Avian Diseases, Jacksonville, v. 36, n. 3, p. 788-791, 1992.

DUNCAN, R. The low pH-dependent entry of avian reovirus is accompanied by two specific cleavages of the major outer capsid protein 42C. Virology, New York, n. 219, p. 179-189, 1996.

ENDO-MUNOZ, L. B. A western blot to detect antibody to avian reovirus. Avian Pathology, Abingdon, v. 19, n. 3, p. 477-487, 1990.

ENGSTRÖM, B. E.; FOSSUM, O.; LUTHMAN, M. Blue wing disease of chickens: experimental infection with a Swedish isolate of chicken anaemia agent and an avian reovirus. Avian Pathology, Abingdon, v. 17, n. 1, p. 33-50, 1988.

FARREL, D. The role of poultry in human nutrition. In: FAO FOOD AND AGRICULTURE ORGANIZATION OF THE UNITED NATIONS. Poultry Development Review. Rome: FAO, 2013 a. p. 2-3.

The nutritional benefits of chicken meat compared with other meats. In: FAO - FOOD AND AGRICULTURE ORGANIZATION OF THE UNITED NATIONS. Poultry Development Review. Rome: FAO, 2013b. p. 4.

GOLDENBERG, D. et al. Genetic and antigenic characterization of sigma $C$ protein from avian reovirus. Avian Pathology, Abingdon, v. 39, n. 3, p. 189-199, 2010.

Differentiating infected from vaccinated animals, and among virulent prototypes of reovirus. Journal of Virological Methods, Amsterdam, v. 177, n. 1, p. 80-86, 2011.

Optimized polypeptide for a subunit vaccine against avian reovirus. Vaccine, Amsterdam, v. 34, n. 27, p. 3178-3183, 2016.

GOODWIN, M. A. et al. Enteritis (so-called Runting Stunting Syndrome) in Georgia broiler chicks. Avian Diseases, Jacksonville, v. 37, n. 2, p. 451-458, 1993.

GRANDE, A. et al. Oligomerization and cell-binding properties of the avian reovirus cell-attachment protein $\sigma C$. Virology, New York, v. 274, n; 2 , p. 367-377, 2000.

GRANDE, A.; BENAVENTE, J. Optimal conditions for the growth, purification and storage of the avian reovirus S1133. Journal of Virological Methods, Amsterdam, v. 85, p. 43-54, 2000.
HIERONYMUS, R. K.; VILLEGAS, P.; KLEVEN, S. H. Identification and serological differentiation of several reovirus strains isolated from chickens with suspected malabsorption syndrome. Avian Diseases, Jacksonville, v. 72, n. 1, p. 246-254, 1983.

HILL, J. E. et al. Ultrastructure of the gastrocnemius tendon and sheath from broilers infected with reovirus. Avian Diseases, Jacksonville, n. 33, n. 1, p. 79-85, 1989.

HOLLMÉN, T. et al. Isolation and characterization of a reovirus from common eiders (Somateria mollissima) from Finland. Avian Diseases, Jacksonville, v. 46, n. 2, p. 478-484, 2002.

HUANG, L. et al. A duplex real-time PCR assay for the detection and quantification of avian reovirus and Mycoplasma synoviae. Virology Journal, New York, v. 12, n. 22, 2015.

$I D E, \quad P . \quad R$. Avian reovirus antibody assay by indirect immunofluorescence using plastic microculture plates. The Canadian Journal of Comparative Medicine, Gardenvale, v. 46, n. 2, p. 39-42, 1982.

JONES, R. C. Avian reovirus infections. Revue scientifique et technique (International Office of Epizootics), Paris, v. 19, n. 2, p. 614-625, 2000.

Reovirus Infections. In: SAIF, Y. M. et al. (Eds.). Diseases of poultry. 12. ed. Hoboken: Wiley, 2008. p. 311-314.

JONES, R. C.; GEORGIOU, K. Reovirus-induced tenosynovitis in chickens the influence of age at infection. Avian Pathology, Abingdon, v. 13, n. 3, p. 441-457, 1984a.

The temporal distribution of an arthrotropic reovirus in the leg of the chicken after oral infection. Avian Pathology, Abingdon, v. 14, n. 1, p. $75-85,1984 b$.

JONES, R. C.; GUNERATNE, J. R. M. The pathogenicity of some avian reoviruses with particular reference to tenosynovitis. Avian Pathology, Abingdon, v. 13, p. 173-189, 1984.

JONES, R. C.; ONUNKWO, O. Studies on experimental tenosynovitis in light hybrid chickens. Avian Pathology, Abingdon, v. 7, n. 1, p. 171-181, 1978.

KANT, A. et al. Classification of Dutch and German avian reoviruses by sequencing the $\sigma C$ protein. Veterinary Research, New York, v. 34, n. 2, p. 203-212, 2003.

KORT, Y. H. et al. Genotyping and classification of Tunisian strains of avian reovirus using RT-PCR and RFLP analysis. Avian Diseases, Jacksonville, v. 59, n. 1, p. 14-19, 2015.

LAWSON, B. et al. Mortality associated with avian reovirus infection in a free-living magpie (Pica pica) in Great Britain. BCM Veterinary Research, London, v. 11, n. 20, p. 2-7, 2015.

LIU, H. J. et al. Identification of the $\sigma \mathrm{C}$-encoded gene of avian reovirus by nested PCR and restriction endonuclease analysis. Journal of Virological Methods, Amsterdam, v. 81, p. 83-90, 1999. 
Development of an ELISA for detection of antibodies to avian reovirus in chickens. Journal of Virological Methods, Amsterdam, v. 102, p. 129-138, 2002.

Molecular evolution of avian reovirus: evidence for genetic diversity and reassortment of the S-class genome segments and multiple cocirculating lineages. Virology, New York, v. 314, n. 1, p. 336-349, 2003.

Rapid characterization of avian reoviruses using phylogenetic analysis, reverse transcription-polymerase chain reaction and restriction enzyme fragment length polymorphism. Avian Pathology, Abingdon, v. 33, n. 2, p. 171-180, 2004.

LIU, H. J.; GIAMBRONE, J. J.; NIELSEN, B. L. Molecular characterization of avian reovirus using nested PCR and nucleotide sequence analysis. Journal of Virological Methods, Amsterdam, v. 65, n. 2, p. 159-167, 1997.

LUBLIN, A. et al. Wide-range protection against avian reovirus conferred by vaccination with representatives of four defined genotypes. Vaccine, Amsterdam, v. 29, n. 47, p. 8683-8688, 2011.

MALKINSON, M.; PERK, K.; WEISMAN, Y. Reovirus infection of young Muscovy ducks (Cairina moschata). Avian Pathology, Abingdon, v. 10, n. 4, p. 433-440, 1981.

MARTÍNEZ-COSTAS, J. et al. Protein architecture of avian reovirus S1133 and identification of the cell attachment protein. Journal of Virology, Washington, DC, v. 71, n. 1, p. 59-64, 1997.

MARTÍNEZ-COSTAS, J.; VARELA, R.; BENAVENTE, J. Endogenous enzymatic activities of the avian reovirus S1133: identification of the viral capping enzyme. Virology, New York, v. 206, n. 2, p. 1017-1026, 1995.

MEANGER, J. et al. Tissue tropism of avian reoviruses is genetically determined. Veterinary Research, Amsterdam, v. 30, n. 5, p. 523529, 1999.

METTIFOGO, E. et al. Emergence of enteric viruses in production chickens is a concern for avian health. The Scientific World Journal, London, v. 2014, p. 1-8, 2014.

MUKIIBI-MUKA, G.; JONES, R. C. Local and systemic IgA and IgG responses of chicks to avian reovirus: effects of age of chick, route of infection and virus strain. Avian Pathology, Abingdon, v. 28, n. 1, p. 54-60, 1999.

NEIGHBOR, N. K. et al. The effect of microaerosolized hydrogen peroxide on bacterial and viral poultry pathogens. Poultry Science, Oxford, v. 73, n. 10, p. 1511-1516, 1994.

NI, Y.; RAMIG, R. F.; KEMP, M. Identification of proteins encoded by avian reoviruses and evidence for post-translational modifications. Virology, New York, v. 193, n. 1, p. 466-469, 1993.

OLIVEIRA, A. A. et al. Principais causas de condenação ao abate de aves em matadouros frigoríficos registrados no serviço brasileiro de inspeção federal entre 2006 e 2011. Ciência Animal Brasileira, Goiânia, v. 17, n. 1, p. 79-89, 2016.
OLSON, N. O.; KERR, K. M. The duration and distribution of synovitis-producing agent in chickens. Avian Diseases, Jacksonville, v. 11, n. 4., p. 578-585, 1967.

OWADE, A. A.; DUCATEZ, M. F.; MULLER, C. P. Seroprevalence of avian influenza virus, infectious bronchitis virus, reovirus, avian pneumovirus, infectious laryngotracheitis virus and avian leukosis virus in Nigerian poultry. Avian Diseases, Jacksonville, v. 50, n. 2, p. 222-227, 2006.

PALYA, V. et al. Reovirus identified as cause of disease in young geese. Avian Pathology, Abingdon, v. 32, n. 2, p. 129-138, 2003.

PANTIN-JACKWOOD, M. J. et al. Enteric viruses detected by molecular methods in commercial chicken and turkey flocks in the United States between 2005 and 2006. Avian Diseases, Jacksonville, v. 52, n. 2, p. 235-244, 2008.

PU, J. et al. Seroprevalence of avian reovirus in egg-laying chicken flocks in China. Avian Diseases, Jacksonville, v. 52, n. 4, p. 657679, 2008.

RAU, W. E. et al. Onset of progeny immunity against viral arthritis/ tenosynovitis after experimental vaccination of parent breeder chickens and cross-immunity against six reovirus isolates. Avian Diseases, Jacksonville, v. 24, n. 3, p. 648-657, 1980.

RECK, C. et al. Rapid detection of Mycoplasma synoviae and avian reovirus in clinical samples of poultry using multiplex PCR. Avian Diseases, Jacksonville, v. 57, n. 2, p. 220-224, 2013.

REVOlledO, L.; FERREIRA, A. J. O. Patologia Aviária. Barueri: Manole, 2009. 510 p.

RIOS, R. L. et al. The occurence of Orthoreovirus, Rotavirus and chicken anemia virus in chickens of the poultry industry in Minas Gerais, Brazil. Arquivo Brasileiro de Medicina Veterinária e Zootecnia, Belo Horizonte, v. 64, n. 6, p. 1613-1620, 2012.

ROBERTSON, M. D.; WILCOX, G. E. Serological characteristics of avian reoviruses of Australian origin. Avian Pathology, Abingdon, v. 13, n. 3, p. 585-594, 1984.

ROBERTSON, M. D.; WILCOX, G. E.; KIBENGE, F. S. B. Prevalence of reoviruses in commercial chickens. Australian Veterinary Journal, Hoboken, v. 61, n. 10, p. 319-322, 1984.

ROESSLER, D. E.; ROSENBERGER, J. L. In vitro and in vivo characterization of avian reoviruses. III. Host factors affecting virulence and persistence. Avian Diseases, Jacksonville, v. 33, n. 3, p. $555-565,1989$.

ROSENBERGER, J. K. et al. In vitro and in vivo characterization of avian reoviruses. I. Pathogenicity and antigenic relatedness of several avian reovirus isolates. Avian Diseases, Jacksonville, v. 33, n. 3. p. 535-544, 1989.

SÁNCHEZ-CORDÓN, P. J. et al. Reovirus infection in psittacine birds (Psittacus erithacus): morphologic and immunohistochemical study. Avian Diseases, Jacksonville, v. 46, n. 2 , p. $485-492,2002$. 
SANTOS, H. F. et al. Anticorpos contra vírus em galinhas de terreiro do Estado do rio Grande do Sul, Brasil. Ciência Rural, Santa Maria, v. 38, n. 7, p. 1932-1937, 2008.

Anticorpos contra vírus de galinha em cracídeos. Ciência Rural, Santa Maria, v. 39, n. 7, p. 2225-2228, 2009.

SAVAGE, C. E.; JONES, R. C. The survival of avian reoviruses on materials associated with the poultry house environment. Avian Pathology, Abingdon, v. 32, n. 4, p. 419-425, 2003.

SHIEN, J. H.; YIN, H. S.; LEE, L. H. An enzyme-linked immunosorbent assay for the detection of antibody to avian reovirus by using protein $\sigma \mathrm{B}$ as the coating antigen. Research in Veterinary Science, Amsterdam, v. 69, p. 107-112, 2000.

SILVA, R. R. Detecção, epidemiologia e análise molecular de rotavírus, picobirnavírus e reovírus em aves de corte criadas em granjas na mesorregião metropolitana de Belém, Pará, Brasil. 2012. 153 f. Tese (Doutorado em Doenças Tropicais) - Núcleo de Medicina Tropical, Universidade Federal do Pará, Belém, 2012.

SILVERSTEIN, S. C.; SCHUR, P. H. Immunofluorescent localization of double-stranded RNA in reovirus-infected cells. Virology, New York, v. 41, n. 3, p. 564-566, 1970.

TAMEHIRO, C. Y. et al. Segmented double-stranded genomic RNA viruses in fecal samples from broiler chicken. Brazilian Journal of Microbiology, São Paulo, v. 34, n. 4, p. 349-353, 2003.

TANYI, J. et al. Pancreatitis caused by reovirus in guinea-fowl. Avian Pathology, Abingdon, v. 23, n. 1, p. 61-77, 1994.

TROXLER, S. et al. Identification of a new reovirus causing substantial losses in broiler production in France, despite routine vaccination of breeders. Veterinary Record, London, v. 172, n. 21, p. 556, 2013.

TSAI, H. J.; LEE, C. Y. Serological survey of racing pigeons for selected pathogens in Taiwan. Acta Veterinaria Hungarica, Budapest, v. 54, n. 2, p. 179-189, 2006.

VAN DE ZANDE, S.; KUHN, E. M. Central nervous system signs in chickens caused by a new avian reovirus strain: a pathogenesis study. Veterinary Microbiology, Amsterdam, v. 120, n. 1, p. 4249, 2007.
VAN DEN BRAND, J. M. A. et al. Reovirus infections associated with high mortality in psittaciformes in the Netherlands. Avian Pathology, Abingdon, v. 36, n. 4, p. 293-299, 2007.

VAN DER HEIDE, L.; KALBAC, M.; BRUSTOLON, M. Development of attenuated apathogenic reovirus vaccine against viral arthritis/ tenosynovitis. Avian Diseases, Jacksonville, v. 27, n. 3, p. 698-706, 1983.

VAN DER HEIDE, L.; KALBAC, M.; HALL, W. C. Infectious tenosynovitis (viral arthritis): influence of maternal antibodies on the development of tenosynovitis lesions after experimental infection by day-old chickens with tenosynovitis virus. Avian Diseases, Jacksonville, v. 20, n. 4, p. 641-648, 1976.

VAN LOON, A. A. et al. The contribution of humoral immunity to the control of avian reoviral infection in chickens after vaccination with live reovirus vaccine (strain 2177) at an early age. Avian Pathology, Abingdon, v. 32, n. 1, p. 15-23, 2003.

VARELA, R.; BENAVENTE, J. Protein coding assignment of avian reovirus strain $\mathrm{S1133}$. Journal of Virology, Washington, DC, v. 68 , n. 10, p. $6775-6777,1994$.

VASCONCELOS, S. B. S. et al. Lesões articulares em frangos de corte (Gallus gallus) na infecção experimental pelo reovírus aviário. Brazilian Journal of Veterinary Research and Animal Science, São Paulo, v. 38, n. 2, p. 80-83, 2001.

WOOD, G. W. et al. Serological comparisons of avian reoviruses. Journal of Comparative Pathology, Amsterdam, v. 90, n. 1, p. 2938,1980 .

XIE, Z. et al. Recombinant protein-based ELISA for detection and differentiation of antibodies against avian reovirus in vaccinated and non-vaccinated chickens. Journal of Virological Methods, Amsterdam, v. 165, n. 1, p. 108-111, 2010.

YANG, Z. J. et al. Development of ELISA kits for antibodies against avian reovirus using the $\sigma \mathrm{C}$ and $\sigma \mathrm{B}$ proteins expressed in the methyltropic yeast Pichia pastoris. Journal of Virological Methods, Amsterdam, v. 163, n. 2, p. 169-174, 2010.

ZHANG, X. et al. Structure of avian orthoreovirus virion by electron cryomicroscopy and image reconstruction. Virology, New York, v. 343, n. 1, p. 25-35, 2005. 